\title{
sciendo
}

\section{John Searle's Naturalism as a Hybrid (Property-Substance) Version of Naturalistic Psychophysical Dualism}

\author{
Dmytro Sepetyi \\ Zaporizhzhia State Medical University
}

DOI: $10.2478 /$ disp-2019-0003

BIBLID [0873-626X (2019) 52; pp.23-44]

\begin{abstract}
The article discusses the relationship between John Searle's doctrine of naturalism and various forms of materialism and dualism. It is argued that despite Searle's protestations, his doctrine is not substantially different from the epiphenomenalistic property dualism, except for the admission, in his later works, of the existence of an irreducible non-Humean self. In particular, his recognition that consciousness is unique in having an irreducible first-person ontology makes his disavowal of property dualism purely verbalistic. As for epiphenomenalism, Searle's explanation of how consciousness can be efficacious without violating the causal closure of the physical, by analogy with the causal efficacy of the higher level properties of physical objects that are supervenient on the microphysical, confuses causality and constitution (causal and constitutive supervenience). It is also argued that Searle's recognition of the existence of an irreducible non-Humean self that is responsible for decision-making sits badly both with his (property dualistic) view that conscious mental states are irreducibly first-personal states of the brain (rather than of the self) and with his (epiphenomenalistic) view that consciousness has no causal power in addition to that of the underlying neurobiology.
\end{abstract}

Keywords

Consciousness, naturalism, materialism, dualism, epiphenomenalism.

John Searle is an eminent contemporary philosopher who made several important contributions to philosophy of mind, such as his research on intentionality and the influential argument against functionalism (or the theory of Strong Artificial Intelligence, according to which the human brain is a computer, and human thinking and understanding consist in the execution of some algorithm by this 
computer), the Chinese room thought experiment. Besides, Searle ambitiously proposes and defends - as the solution of the mind-body problem - the general ontological conception that he calls "naturalism". Searle presents it as a new view that is an alternative to all traditional directions, especially the two most influential, materialism and dualism. This naturally evokes interest, because each of the traditional directions comes across pretty serious problems and objections. Now if a distinguished contemporary philosopher of mind claims that he proposes an alternative that is free from the main drawbacks of the traditional directions, and persists in this claim for many years, it seems that this requires examination. Perhaps, Searle has really discovered a satisfactory new solution to the problem on which philosophers were disputing for many centuries?

Searle's claim is especially remarkable because he contends that his view, which he calls "naturalism" or "biological naturalism", reconciles three positions that before him were considered incompatible:

(1) the ontological irreducibility of phenomenal (conscious) mental states to the physical;

(2) the causal closure of the physical;

(3) the causal efficacy of consciousness (phenomenal mental states) with respect to the physical.

Each one of these positions, taken separately, seems very plausible, and pretty good arguments in its favour can be provided; however, it seems that all these three positions together are incompatible; at least one of them should be false. Or so it was, and still is, believed by almost all philosophers of mind, except Searle. Accordingly, they believe that we must abandon at least one of these positions, acknowledge its falsity. To abandon the first position is to hold materialism. To abandon the second position (while keeping the first and the third ones) is to subscribe to the dualistic doctrine of interactionism. To abandon the third position (while keeping the first and the second ones) is to subscribe to the dualistic doctrine of epiphenomenalism. Searle rejects all these options and believes that we should not abandon anything - that we can hold all the three positions together, and this will be his view, naturalism. Let us designate this as the Compatibility Claim. 
However, quite a few other philosophers (see, for example, Nagel 1995: 96, Chalmers 1996: 164, 370, 376, Velmans 2000: 39, Feser 2004), on considering Searle's explanations, have arrived at the conclusion that he fails to fulfil his promise, and that his view is not really new: it is a variety of dualistic philosophy, namely, property dualism, and more precisely, epiphenomenalism. Searle (2002; 2004: 75-92; 2007) emphatically denies this but fails to convince others.

The purpose of this article is to clarify Searle's views and their real relation to main varieties of materialism and dualism. My analysis provides support for the case of Searle's critics. In general, it agrees with the argument made by Edward Feser (2004), but supplements and updates it in some respects. First, I point out and explain that Searle's defences of the Compatibility Claim are grounded on the confusion between the notions of causation and constitution, which is especially prominent in his treatment of superveniencethe failure to see the relevance of the constitutional notion and the mistaken insistence that only the causal notion matters for the mindbody problem. Second, I discuss Searle's later defence of the Compatibility Claim, in terms of "conscious events" that involve both neurobiology and consciousness (Searle 2007), and argue that it is untenable. Third, I take into account an important new feature of Searle's philosophy that first appears in his book Rationality in Action (Searle 2001) - the recognition of the existence of an irreducible non-Humean self, which makes Searle's view sort of a hybrid between property dualism and substance dualism.

\section{Background: the traditional directions in the philosophy of mind. Naturalistic (emergentistic) dualism}

The main alternatives in the contemporary philosophy of mind are several forms of materialism (the identity theory, functionalism, and eliminativism) and dualism (property dualism and substance dualism, in theistic and naturalistic varieties), as well as panpsychism and idealism. To classify Searle's view correctly, we should pay attention to the existence of naturalistic (emergentistic) brands of dualism - property dualism, which considers phenomenal mental states as natural but non-physical properties or states of the brain (such that 
exist in addition to all physical but, of course, cannot exist without the brain of which they are properties or states), ${ }^{1}$ and naturalistic substance or quasi-substance dualism, which acknowledges the existence of non-physical mental entities (selves) as bearers of phenomenal mental states and performers of thinking and volition (unlike a "Humean" self, which is nothing but a "stream" or "bundle" of phenomenal mental states, experiences) but does not hold that they can exist (in the sense of natural possibility, in the actual world rather than in some logically possible worlds) without a functioning brain or some relevantly similar material system. ${ }^{2}$

It is clear that Searle's view is neither functionalism, nor eliminativism, nor panpsychism, nor idealism. The question of its relation to the materialist theory of identity (of mental states with some physical states of the brain), property dualism and naturalistic (quasi-)substance dualism is more complicated.

\footnotetext{
${ }^{1}$ Some examples of property dualism are Frank Jackson's views between 1982 and 1998 (see Jackson 1982, 1986) and the views David Chalmers defended in The Conscious Mind (1996).

2 The choice between the adjectives "substance" and "quasi-substance" depends on whether we understand the noun "substance" to mean just "a bearer of properties and states", without any further constraints (as some contemporary authors do; see, for example, Moreland 1987: 79, Lowe 2000: 9), or in the more restrictive sense that adds the requirement that a substance should be capable of independent existence (without other substances except God), as in Descartes' classical substance dualism. We can use "naturalistic substance dualism" and "quasi-substance dualism" as synonyms, because the adjective "naturalistic", as well as the prefix "quasi-", indicates in this context that the adherents of this version of dualism believe that a mental subject is something non-physical (ontologically irreducible to anything physical) but natural, and exists only in alliance with a functioning brain. An example of naturalistic substance or quasi-substance dualism was Karl Popper's view (see, especially, his and Eccles' The Self and Its Brain (Popper and Eccles 1977)). Also David Chalmers, in the last statement on this point I met, described his sympathies in philosophy of mind as being divided between Russellian monism (in the forms of panpsychism or panprotopsychism) and (naturalistic) substance dualism (Chalmers 2013: 26).
} 


\section{Why Searle is not a materialist}

Searle denounces materialism, but many his statements are likely to create the impression that this is a misunderstanding and that his "naturalism" is in fact a form of materialism. Like Karl Vogt, a materialist of $20^{\text {th }}$ century who is remembered for his statement that "the brain produces thought like the liver produces bile", Searle stated that "consciousness is a biological feature of the brain in the same way that digestion is a biological feature of the digestive tract" (Searle 2004: 81). In the book The Rediscovery of the Mind, Searle explains his views as follows:

The brain causes certain "mental" phenomena, such as conscious mental states, and these conscious states are simply higher-level features of the brain. Consciousness is a higher-level or emergent property of the brain in the utterly harmless sense of "higher-level" or "emergent" in which solidity is a higher-level emergent property of $\mathrm{H}_{2} \mathrm{O}$ molecules when they are in a lattice structure (ice), and liquidity is similarly a higher-level emergent property of $\mathrm{H}_{2} \mathrm{O}$ molecules when they are, roughly speaking, rolling around on each other (water). Consciousness is a mental, and therefore physical, property of the brain in the sense in which liquidity is a property of systems of molecules. (Searle 1992: 14)

Statements in the same vein are made also in Searle's later works. In particular, in the book Mind he writes:

Consciousness is a system-level, biological feature in much the same way that digestion, or growth, or the secretion of bile are system level, biological features. As such, consciousness is a feature of the brain and thus a part of the physical world. ... consciousness is a biological feature of the brain in the same way that digestion is a biological feature of the digestive tract. (Searle 2004: 80-1).

Most materialists (especially, supporters of the identity theory, which directly identifies mental states with certain physiological brain states) would gladly subscribe to this statement, and it is difficult to see how it can agree with the denial of materialism. However, these seemingly incompatible positions are both held by Searle.

In Mind, a bit before the above adduced quotation, Searle acknowledges that conscious mental states are, after all, essentially different from other natural phenomena, such as the solidity of ice, 
the liquidity of water, lactation, photosynthesis, digestion, etc. Unlike all this, phenomenal (conscious) mental states have "a subjective or first-person ontology" (Searle 2004: 78), and so they "are not ontologically reducible to third-person phenomena" (Searle 2004: 80), that is, to a physical (neurobiological) basis: "We cannot ... reduce consciousness to its neurobiological basis, because such a third-person reduction would leave out the first-person ontology of consciousness" (Searle 2004: 79) — that is, it would leave out exactly what makes consciousness (the phenomenal, subjective) so special and problematic for materialism.

It seems that from the ontological irreducibility of phenomenal mental states as having a first-person ontology, it obviously follows that they are something fundamentally different from all other natural phenomena (which have the third-person ontology and therefore are reducible to a microphysical basis) — something besides, in addition to anything that has only the third-person ontology, that is, to anything physical (material). But this means dualism (at least, property dualism), which (as well as materialism) Searle repudiates!

\section{Is Searle's view really different from property dualism?}

So Searle, like property dualism, acknowledges that consciousness has an irreducible subjective (first-person) ontology, whereas everything in which consciousness is not involved has the purely objective (third-person) ontology, is ontologically reducible to the microphysical. He also acknowledges, and especially emphasizes, that what has the subjective (first-person) ontology (i.e., consciousness) is just as real as what has the objective (third-person) ontology, that is, physical reality. Given their mutual irreducibility, this means an ontologically fundamental division of properties into two categories. In all this, Searle's view and property dualism agree. If so, what is supposed to be the difference?

Searle explains that the difference is that property dualists conclude from the ontological irreducibility of mental states (as having the first-person ontology) that consciousness is something distinct from the neurobiology that causes it, and from anything physical, something "over and above", whereas he denies this conclusion. But how can one acknowledge that consciousness is ontologically irreducible, is not identical with the neurobiological states that give rise 
to it, and at the same time deny that it is distinct from them, something in addition to ("over and above") them? Is not this the same meaning put in different words? At least, property dualists and other participants of the discussion, except for Searle, when they assert or deny that consciousness is distinct from those neurobiological processes that give rise to it, is something in addition to them, understand by distinctness and additionality (over-and-aboveness) nothing but ontological irreducibility, non-identity, and this agrees with the usual meanings of the words and phrases "distinct from", "in addition to", "over and above". If Searle acknowledges the ontological irreducibility, the non-identity of consciousness to the underlying neurobiology but denies their distinctness, this can mean only that he uses the word "distinct" in a peculiar meaning different from the common one. However, this does not make his view (its meaning) different. Only the usage of words is different.

To avoid identifying his position with property dualism, Searle emphasizes that "[c]onscious states are entirely caused by lower level neurobiological processes in the brain" (italics mine), and proceeds to the statement that they "have absolutely no life of their own, independent of the neurobiology", and hence, "[c]ausally speaking, they are not something 'over and above' neurobiological processes" (Searle 2004: 80). While acknowledging that consciousness is ontologically irreducible to physical (neurobiological) processes in the brain, Searle, however, insists that it is causally reducible to (causally supervenient on) a neurobiological basis. However, this means only that conscious mental states are caused by some neurobiological states (processes), and property dualism claims the same. The very content of property dualism is just this: consciousness is a complex of properties or states that are ontologically irreducible to (and so distinct from) physical processes, although they are caused by some physical (neurobiological) states of the brain.

The fact that mental states are caused by some neurobiological states (processes) does not prevent their being something else, distinct from, in addition to neurobiological processes. "A causes B" does not mean "A is B". On the usual use of the notion of causality, exactly opposite is the case: when we say that A causes B, we usually mean that $\mathrm{A}$ and $\mathrm{B}$ are not the same thing (at different levels of description); we mean that $\mathrm{A}$, which causes $\mathrm{B}$, and $\mathrm{B}$, which is an effect of 
A, are different things (states, events, etc.).

If neurobiological states of the brain cause mental states as something else, irreducible to themselves (rather that constitute mental states in a way analogous to how microphysical elements, relations, and processes constitute higher-level material phenomena), then it is a matter of relationship between different entities, one of which (neurobiological) is the cause, and the other (mental) is an effect. The sense of psychophysical dualism consists exactly in this statement: mental states and physical (brain) states are fundamentally different, distinct, no matter how close their causal connection! Searle's insistence that an ontologically irreducible effect is not something "over and above" its cause seems to be falling into linguistic extravagance rather than proposing a genuinely new view.

\section{Words do not matter, meanings do}

One of Searle's key points is that for the correct solution of the mindbody problem (which he purports to propose), it is necessary to abandon the "traditional Cartesian categories", which are accepted by both materialists and dualists. However, the careful examination of his explanations gives reasons to doubt that, as a result, we obtain a substantially original position rather than a masked (by changed ways of using philosophical terms) version of one of the doctrines Searle claims to reject.

Searle describes his (purported) opposition to both materialism and dualism as follows:

The tradition that I am militating against says that because mental states are intrinsically mental, they cannot be in that very respect, physical. I am in effect saying that because they are intrinsically mental, they are a certain type of biological state, and therefore a fortiori they are physical. However, the whole terminology of mental and physical was designed to try to make an absolute opposition between the mental and the physical, so maybe it is better not to use that terminology at all ... We are in both cases talking about natural processes. (Searle 2004: 80-81)

So the roots of the mind-body problem, according to Searle, are that we use the "Cartesian vocabulary", and it is enough that we abandon it and the problem is solved! (Is not it the case that if we stop calling 
dogs "dogs" and start calling them "cats", they will stop barking and start mowing?)

In fact, serious philosophical problems (such as the mind-body problem) are never solved by changing the terminology. It does not matter how we call what in the standard ("Cartesian") terminology of the contemporary philosophy of mind is called "mental" and "physical". However we call it, the problem and the content of the alternative views on it remain the same. The point at issue is whether (everything of) that which is called "mental" in the standard terminology (or, more precisely, phenomenal, conscious mental states), is identical with or distinct from all that in the standard terminology is called "physical". And Searle's answer seems to be the same (in meaning, whatever are the words) as that given (in traditional terms) by property dualism.

It is worth to pay attention to the explanation of the meaning of materialism given by Joseph Levine, who, in his turn, refers to the explanation by Richard Boyd. According to the latter, "materialism is the doctrine that what goes on in us is ultimately the same as what goes on in tables and chairs, on the assumption that they aren't themselves mental entities"; as for the latter possibility, "[i]f it turns out that deep down there are minds activating their behavior, then all bets are off" (quot. by: Levine 2001: 20). Accordingly, Levine defines materialism as the doctrine that "[o]nly non-mental properties are instantiated in a basic way; all mental properties are instantiated by being realized by the instantiation of other, non-mental properties" (Levine 2001: 20). We can similarly explain the meaning of the main alternative doctrines. Dualism, like materialism, acknowledges that what happens in tables, chairs and all other bodies is, at the fundamental level, nonmental; however, unlike materialism, it holds that in the case of human beings (and, probably, many animals, at least higher ones) there is not only "ultimately the same as what goes on in tables and chairs", but also something fundamentally different. Panpsychism and idealism, on the other hand, deny the assumption (common to materialism and dualism) that all that happens in tables and chairs is fundamentally nonmental.

Accordingly, the traditional meaning of the term "physical" (or "matter") in the context of the mind-body problem is just this: "ultimately the same as what goes on in tables and chairs" (though perhaps 
much more complex). This encompasses ordinary spatially located bodies (for the largest part, inanimate ones) on the macrolevel, and that of which these bodies are composed on the microlevel, on the assumption (that is strongly supported by science) that living and inanimate bodies are ultimately composed of the same components (atoms, leptons, quarks, physical fields, waves, etc.).

Of course, one can use the word "physical" in the extended sense, as a synonym to "natural" (as Searle does in the second sentence of the above quotation), and in this terminology, the naturalistic dualist would agree that mental states are "a certain type of biological state, and therefore a fortiori they are physical". However, while agreeing with this, the naturalistic dualist does not cease to be a naturalistic dualist: it is just that the formulation of naturalistic dualism would require new terms. A naturalistic dualist can call what is usually called "physical" (in the standard sense rather than the extended one) by some other word (for example, "schmysical"), and redesignate his view with a different name (for example, "psychoschmysical dualism", or even "naturalism"); however, such a renaming changes nothing, because the dualist holds, just as before, that phenomenal mental states are non-schmysical, something in addition to all the schmysical there is.

The same goes for the term "neurobiological". Searle explains that the property dualist holds "that in addition to all the neurobiological features of the brain, there is an extra, distinct, nonphysical feature of the brain", whereas he claims to reject this view (Searle 2002: 61). ${ }^{3}$ However, just a paragraph earlier, Searle explained that consciousness is ontologically irreducible, in the sense that the complete description of the features of the brain that have the objective ontology would not contain a description of the features of the brain that have the subjective (first-person) ontology. But saying this is the same as saying that features that have the objective ontology are not all the features of the brain; that besides them (in addition to

\footnotetext{
${ }^{3}$ It is remarkable, and characteristic of Searle's confusion that in his last exposition of his views vis-à-vis materialism and dualism, although his views suffered no revision, Searle admits exactly what he attributed to substance dualists and claimed to deny in (Searle 2002: 61), that "in addition to the neuron firings, the computer programs, the behavior, etc., there are my subjective, qualitative conscious states" (Searle 2007: 177) (italics mine).
} 
them) there are in the brain also features that have the subjective (first-person) ontology. And this is precisely the meaning of the view called "property dualism" - the view Searle claims to reject. If the property dualist says "that in addition to all the neurobiological features of the brain, there is an extra, distinct, nonphysical feature of the brain", she means by "the neurobiological features of the brain" exactly those features that have the objective ontology and by "an extra, distinct, nonphysical feature of the brain" - those features that are ontologically irreducible to the features that have the objective ontology. Of course, Searle can use the word "neurobiological" in another, extended meaning that covers both groups of features (properties); however, this will not be another philosophical view on the mind-body problem - this will be merely another way of using the word. As Edward Feser rightly remarks, "[t]he words may be different, but the metaphysical pictures are identical" (Feser 2004).

Searle explains the fact that other philosophers fail to see or understand the apparently simple and obvious solution of the mindbody problem he proposes, fail to see any alternative to the main traditional views (such as materialism, dualism, idealism, panpsychism) "[b]ecause the traditional vocabulary tells us that the mental and the physical are two distinct ontological categories and because consciousness is not ontologically reducible to its neuronal base" (Searle 2002: 62). However, this explanation is inadequate in the first part (about the dictionary); this part is entirely superfluous: in fact, all that matters is whether consciousness is (as materialists hold) or is not (as dualists hold) ontologically reducible to its neuronal (and generally physical) base. Acknowledgement or denial of the ontological irreducibility of consciousness to any physical basis is the demarcation line between dualism (or, perhaps, idealism or panpsychism) and materialism. Traditional Cartesian vocabulary is not guilty of anything; it only reflects this real or apparent ontological irreducibility of consciousness to (its distinctness from) the physical.

As Edward Feser explains,

... the distinction on which property dualism rests - that between irreducibly subjective and objective phenomena - is one that Searle himself is committed to as marking out two objective categories of phenomena in the universe. ... It is also beside the point whether one wants to go on to label these two categories "non-physical" and "physi- 
cal" - this is a purely semantic issue, the distinction being real whatever one chooses to call it (Feser 2004).

The reason for opposing the mental (as non-physical) to the physical is just that on the view of dualists, "mental phenomena are ... uniquely subjective and therefore uniquely ontologically irreducible", whereas all physical phenomena are objective and ontologically reducible to the non-mental (microphysical) basis, - the point with which Searle agrees. Therefore, Searle's view on the role of the Cartesian vocabulary in the mind-body problem is mistaken: "It is just not true that Descartes or anyone else decided one day capriciously to define 'mental' to mean 'non-physical,' and then concluded, trivially, that some form of dualism must be true" (Feser 2004).

\section{Is Searle's view different from epiphenomenalism?}

Epiphenomenalism is a variety of psychophysical dualism (usually, property dualism) that acknowledges that conscious mental states are nonphysical (nonphysical states of the brain), and, at the same time, holds that physical reality is causally closed: all physical events have physical causes; nothing nonphysical affects them. In other words, consciousness is causally inefficacious with respect to the physical.

Searle claims that his view is different: consciousness is causally efficacious. But at the same time, he asserts that "consciousness has no causal powers of its own in addition to the causal powers of the underlying neurobiology" (Searle 2002: 60) (almost literally the same: Searle 2004: 80). That is, when speaking about the causal efficacy of consciousness, Searle really means the causal efficacy not of consciousness itself, as something that has an irreducible first-person ontology and so is ontologically irreducible to its neurobiological basis; he means the causal efficacy of the neurobiological basis of consciousness, those neurobiological processes that cause consciousness.

How can one hold both the view that consciousness is causally efficacious, and the view that it "has no causal powers of its own in addition to the causal powers of the underlying neurobiology"? Searle attempts to do this by appealing to the concept of supervenience. He holds that consciousness (phenomenal mental states) is a natural phenomenon that is supervenient on physical structures and 
processes in the brain. In the contemporary philosophy of mind, the term "supervenience" means the following: A is supervenient on B, if all that belongs to A is determined by (corresponds to) something that belongs to $\mathrm{B}$, so that it is impossible that something changes in A without there being the corresponding changes in B. For example, all properties of water are supervenient on the properties and (dynamically changing) spatial relations of $\mathrm{H}_{2} \mathrm{O}$ molecules, $\mathrm{H}^{+}$and $\mathrm{OH}^{-}$ ions, etc., from which water is composed. Searle notes that from the late 1970s on (mostly under the influence of Jaegwon Kim's works (1978, 1984, 1990, 1993), philosophers often describe the relation of the mind to physical states of the brain by the statement that mental states are supervenient on the physical (neurobiological). This means that "mental states are totally dependent on corresponding neurobiological states in the sense that a difference in mental states would necessarily involve a corresponding difference in neurobiological states". Any change in mental states is due to the corresponding changes in physical (neurobiological) states of the brain. In other words, the supervenience of the mental on the physical (neurobiological) means that "sameness of neurobiology guarantees sameness of mentality". Searle's own view is that "mental states are supervenient on neurobiological states in the following respect: Type-identical neurobiological causes would have type-identical mentalistic effects" (Searle 1992: 124).

Searle mentions the existence of "at least two notions of supervenience: a constitutive notion and a causal notion", ${ }^{4}$ and emphasizes that he acknowledges that mental states are supervenient on the physical (neurobiological) in the sense of causal supervenience. Moreover, Searle claims that "only the causal notion is important for discussions of the mind-body problem" (Searle 1992: 125), and merely ignores the well-reasoned view of other philosophers that the constitutive notion of supervenience is at least as much important for such discussions (in particular, see Chalmers 1996: 34-42). This is important for Searle's proposed solution of the problem of the causal

\footnotetext{
${ }^{4}$ In the contemporary philosophy of mind, other terms are also used: "logical supervenience" as a synonym to "constitutive supervenience"; "natural supervenience", "nomic supervenience", or "nomological supervenience" as a synonym to "causal supervenience" (see, for example, Chalmers (1996: 34-39)).
} 
efficacy of consciousness with respect to the physical. Searle claims that "the fact that the mental features are supervenient on neuronal features in no way diminishes their causal efficacy. The solidity of the piston is causally supervenient on its molecular structure, but this does not make solidity epiphenomenal" (Searle 1992: 126).

An important point here is the statement that "[t]he solidity of the piston is causally supervenient on its molecular structure" (italics mine). In Searle's explanations, this statement is connected with the concept of "bottom-up, micro to macro forms of causation" (Searle 1992: 126). If we acknowledge that the molecular structure of the piston causes its solidity (or that the molecular structure of water causes its liquidity) and also acknowledge the solidity of the piston as a causal factor (not an epiphenomenon that has no causal efficacy), then, according to Searle, we can just as well acknowledge that neurobiological processes in the brain cause mental states, and mental states are not epiphenomena but are causally efficacious, just as the piston's solidity. And just as the causal efficacy of the solidity of the piston does not contradict the tenet known as "the causal closure of the physical", according to which all physical effects are caused by physical (ultimately, microphysical) causes, so the causal efficacy of consciousness does not contradict it either.

Surprisingly, Searle fails not notice that in the case of the piston, its causal efficacy does not contradict the causal closure of the physical because the piston is nothing but a certain structured multitude of molecules, is reducible to the underlying microphysics, does not have an irreducible ontology. In other words, contrary to Searle, the piston (its properties) is not causally but constitutively supervenient on (the properties and relations of) this multitude of molecules. Because the piston is such a multitude of molecules, the total causal efficacy of this multitude of molecules is the causal efficacy of the piston and its properties (such as solidity). But this cannot be the case with conscious mental states, if we acknowledge (as Searle does) that they have an irreducible (first-person) ontology. If phenomenal mental states are irreducible to the underlying neurobiology, then they are distinct from it, and the causal efficacy of the latter is not the causal efficacy of the former.

With Searle, this surprising neglect of the decisive difference goes hand in glove with the confusion of constitutive and causal relations 
(supervenience). Searle claims that

(1) "only the causal notion [of supervenience] is important for discussions of the mind-body problem" (Searle 1992: 125)

and that

(2) such properties as the piston's solidity or water's liquidity are caused by molecular structure (of the piston or water), are causally supervenient on them.

Arguably, the first claim is false, and the second is either false (if the notions of causal supervenience and constitutive supervenience are taken to be mutually exclusive) or irrelevant (if we use the wide notion of causal supervenience that includes constitutive supervenience). This is so for the following reasons.

The case against (2). In such cases as the solidity of a piston or the liquidity of water, there is not merely causal but constitutive (logical) supervenience on the microphysical. ${ }^{5}$ Generally, all macroproperties of all physical objects are constituted by (constitutively supervenient upon) their molecular structure and other relations between molecules, ions, atoms, etc. (such as the forces of attraction and repulsion, their dependence on distance, etc.) rather than caused by them as something ontologically irreducible. At least, this apparently seems so, and materialists and dualists usually agree on this, and Searle did not deny this explicitly and provided no argument to the contrary. Can Searle hold the view that macroproperties of physical objects also are not constituted by (constitutively supervenient upon) their molecular structure and other relations between molecules, ions, atoms, etc.? This would contradict his admission that consciousness is unique in having the irreducible first-person ontology. And how can macroscopic physical objects with all their properties fail to constitutively supervene upon their microscopic constituents (arranged in

${ }^{5}$ Likewise, Edward Feser points out that the complete description of the physical states and relations of the multitude of $\mathrm{H}_{2} \mathrm{O}$ molecules at temperature below the freezing temperature is the description of the solidity of ice:

There is nothing more to solidity than that; it is identical to the configuration the molecules are in when the object they constitute is at freezing temperature. In any case, there is nothing about the nature of either water molecules or solidity — both of which are "third-person" - that excludes such an identification (Feser 2004). 
certain spatial structures and interacting and moving according to the laws of physics) if the former are entirely composed of the latter? (This is admitted by all sides of discussion, Searle included.)

The case against (1). It is constitutional rather than causal notion of supervenience that is crucial for the mind-body problem. It is so because whereas all macroproperties of all physical objects (such as the solidity of a piston or the liquidity of water) are constituted by (constitutively supervenient upon) the microphysical, it seems that conscious mental states cannot be so constituted, and so are distinct from anything physical. That is what dualists hold and materialists deny. The issue between materialism and dualism is exactly whether or not conscious mental states are constituted by (constitutively supervenient upon) the (micro)physical.

Materialists hold (and dualists deny) that mental states are constituted by physical (neurophysiolgical) processes in the brain. Searle, like dualists, denies this and recognizes that mental states have irreducible first-person ontology, and hence are not constituted by physical (neurobiological) states (processes) of the brain but are caused by them. However, he has somehow managed to overlook the significance of the notion of constitutive supervenience for the mindbody problem. Instead, he had merely mentioned and dismissed this notion.

Of course, we can use the notion of causality, and causal supervenience in some wide sense that will include constitution as well as causal relations between distinct causes and effects (causality and causal supervenience in the usual, narrower sense). In this extended sense, it will be true both that macroproperties of physical objects are (bottom-up) caused by their molecular structure and that conscious mental states are caused by physical processes in the brain. However, such an extended notion of causality would be irrelevant to the mindbody problem, because it blurs the crucial distinction, between the materialistic claim that conscious mental states, like other higherlevel properties of physical objects, are constituted by insentient microphysical entities and their relations, and the dualistic claim that they are not so constituted, are irreducible, distinct from anything physical, even if caused by some physical states. The statement that conscious mental states are causally supervenient on physical processes in the brain, in the extended sense of the notion of causality, (that is, either causally 
supervenient in the usual sense, or constitutively supervenient) does not represent an alternative to materialism and dualism, because it agrees with both. The controversy is not about whether conscious mental states are caused in the extended sense by physical states but about whether the former are constituted by, or ontologically reducible to the latter. If we admit, on one hand, that macroproperties of physical objects are constituted by their molecular structure and other relations between their microscopic components, are constitutively supervenient on a microphysical basis and, on the other hand, that conscious mental states are not so constituted (but are caused, so that cause and effect are distinct), do not supervene constitutively (supervene only causally) on a physical (neurobiological) basis, thereby we accept psychophysical dualism, and so cannot hold that the causal efficacy of consciousness is the causal efficacy of the underlying neurobiology.

In the latest exposition of his views, Searle attempts to defend his claim that consciousness is causally efficacious despite having "no causal powers of its own in addition to the causal powers of the underlying neurobiology" by putting matters in terms of "conscious events", where by "conscious events" he means complex events that involve both neurobiology and consciousness. Conscious events, in this sense, are causally efficacious (Searle 2007: 175-6). However, the problem is that on Searle's account, their causal efficacy is entirely due to their physical (neurobiological) properties, with no contribution of consciousness. To claim that the causal efficacy of conscious events in this sense makes consciousness causally efficacious is like claiming that the power of a red-haired athlete to lift weights means that red-hearedness has weight-lifting power. Or let us recollect the famous epiphenomenalistic metaphor (T. Huxley), of a locomotive engine and a steam-whistle that accompanies its work: does the power of the engine to move locomotives make the steamwhistle powerful in moving locomotives?

Thus, in its real meaning (rather than words), Searle's view does not differ from epiphenomenalism. Searle holds, first, that consciousness is a product of neurobiological processes (is caused by them), second, that consciousness is ontologically irreducible to the physical (neurobiological), and third, that those physical (neurobiological) processes in the brain that cause conscious mental states cause also some other physical (neurobiological) processes; consciousness 
makes to this no causal contribution. Obviously, this means that it has no causal efficacy. Causal links between physical (neurobiological) states and phenomenal mental states (consciousness) go in one direction - from physical to mental; there is no causation in the opposite direction (see Picture 1). This is epiphenomenalism, by the definition of the term.

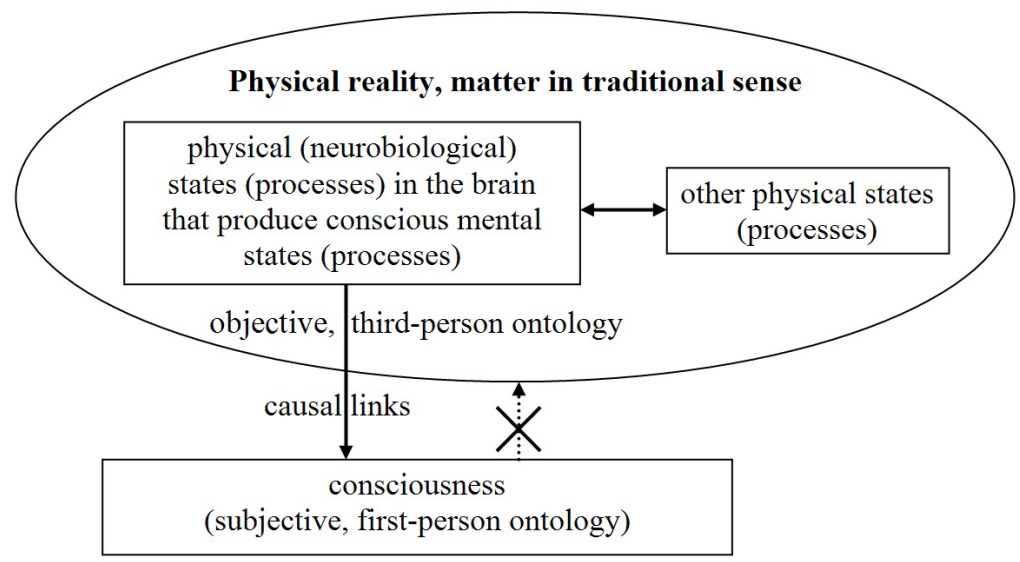

Picture 1. Causal links between physical reality and consciousness according to Searle and epiphenomenalism

However, instead of admitting frankly that on his view, consciousness (phenomenal mental states as such) is a causally inefficacious epiphenomenon (and that his view is epiphenomenalism), Searle proposes anti-Cartesian linguistic reform that consists in using the word "distinct" in some new sense in which an effect does not count as distinct from its cause even if the effect is not ontologically reducible to the cause, and the phrase "causal efficacy" — in a new sense in which "to be causally efficacious" can mean, if translated into the language before the reform, "to have no own causal power but to be produced by something that has such power".

\section{Halfway from property dualism to naturalistic (quasi) substance dualism}

In the book Rationality in Action, Searle comes to admit (with great 
reluctance, as he confesses (Searle 2001: 75, 2004: 201)) the existence of an irreducible non-Humean self (Searle 2001: 61-92). (Searle rehearses the main considerations that had forced him to admit this in the last chapter of a later book, Mind (Searle 2004: 200-6).) This self is irreducible to physical structures and processes (in the traditional sense of the term "physical"), and it is non-Humean - that is, it is not a "bundle" or "stream" of mental states, is irreducible to such states. In Searle's own words, "we need the notion of a self in addition to the notion of particular psychological states and dispositions" (Searle 2004: 200); this self is "in addition to our bodies and the sequence of our experiences" (Searle 2004: 201) (italics mine).

The arguments that have persuaded Searle in the necessity of positing such a self "have to do with the notions of rationality, free choice, decision making, and reasons for action" (Searle 2004: 201). As rational actors, we make decisions on some reasons (considerations for and against), and these reasons are something essentially different from causes: there is always "the causal gap" between, on one hand, the reasons for a decision and, on the other hand, taking and carrying out the decision; unlike causes, which produce their effects in an impersonal way, reasons, however weighty they were, leave me the possibility to make either one decision or another; they can incline me to some decision but not determine it. The causal gap cannot be understood as a matter of pure accident (chance); decisions do not merely arise accidentally from the distribution of probabilities - it is me who makes them. According to Searle, the notion of the self (me) that makes decisions and so fills the causal gap between the reasons for a decision and the decision itself is necessary to make sense of rationality in action, to understand human beings as rational actors that are responsible for their decisions.

Searle makes reservation that this necessarily postulated notion of a self is "formal" rather than "substantive"; however, the explanation he provides is, to my view, not persuasive: he writes that this notion of a self is analogous to the notion of a point of view from which I perceive the world in my experience, only more complex. However, he fails to note that the "formal" notion of a point of view is not irreducible, unlike the self, which Searle admits to be irreducible. If there is irreducible physical reality and there is my irreducible self that makes decisions, and if my experiences are not something "in 
addition" to this self but its mental states, then my experiential point of view is reducible to relations between my self and physical reality (in particular, that special — for me — its part which is my body).

On Searle's account, the irreducible self is merely added to the ontology of epiphenomenalistic property dualism that was discussed in the preceding sections. As a result, we have a queer hybrid between property dualism and substance dualism. Let us compare it with substance dualism proper, as schematized on Picture 2.

the psychophysical ontology according to Searle 2001, Searle 2004

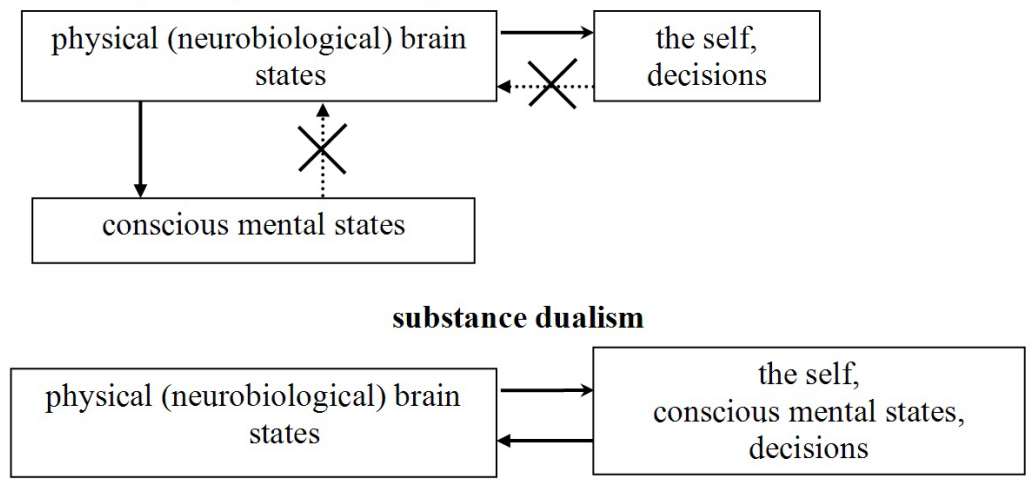

Picture 2. Searle's hybrid ontology and substance dualism

I think that Searle's hybrid ontology is very unnatural, even absurd, in that although the existence of an irreducible (nonphysical) nonHumean self is admitted, conscious mental states are still described as nonphysical states of the brain rather than of the self. If one admits that besides (in addition to) the body, there is the irreducible self that makes decisions, one should hold that conscious mental states are states of this self. All conscious mental states and processesdecision-making as well as thinking, sensing, perceiving, willing, etc.- have, in Searle's terminology, "first-person ontology", where the first person is the same self, I - the one whose mental states they are. To rephrase Descartes, the I that makes decisions is the same I that thinks, senses, perceives, etc. If the existence of an irreducible nonHumean self is admitted, there is no reason (except for the unwillingness to depart from property dualism any more than one is forced by those arguments that made Searle admit the existence of such a 
self) to balk at this "Cartesian intuition" and insist that conscious mental states are states of the brain rather than of that self. Naturalistic (quasi)substance dualism is obviously preferable to such a phenomenologically untenable hybrid between it and property dualism.

In his 2002 article, Searle suggested that one of the deficiencies of property dualism is that "[i]t is not at all easy to see how the property dualist can ... avoid lapsing into substance dualism” (Searle 2002: 63). However, it is even more difficult to see how Searle himself can avoid it while admitting the existence of an irreducible non-Humean self.

Besides, Searle's conclusion about the existence of the irreducible self that makes decisions (fills the gap between the reasons for a decision and the decision itself) is in a strong tension with Searle's acceptance of the tenet of the causal closure of the physical. If physical reality is causally closed, then all our movements, even the minutest ones, are entirely determined (insofar as they are caused at all rather than being merely random) by physical processes in our bodies (brains), and so the irreducible self and all its decision-making cannot have any influence on our behaviour! The self with its decisions should be epiphenomena, just like phenomenal mental states. The notion that we act the way we do because we make certain decisions is an illusion. All that we do are physical effects of physical causes, without any influence of conscious motives and consciously made decisions. Conscious reasons, the self and its decision-making that is motivated but not determined by conscious reasons - all this is but inadequate phenomenal representations in our conscious minds, which are just passive epiphenomena, of some physical (physiological) processes that occur in our brains. Thus, the considerations (concerned with making decisions and acting on them) that made Searle admit the existence of an irreducible (nonphysical) non-Humean self are brought to nothing by his acceptance of the view that physical reality is causally closed.

Dmytro Sepetyi

Zaporizhzhia State Medical University

Ukraine

dmitry.sepety@gmail.com 


\section{References}

Chalmers, David. 1996. The Conscious Mind. New York, Oxford: Oxford University Press.

Chalmers, David. 2013. Panpsychism and panprotopsychism. The Amherst Lecture in Philosophy 8: 1-35. [Online] http://www.amherstlecture.org/ chalmers2013/

Feser, Edward. 2004. Why Searle is a property dualist. [Online] http://www. edwardfeser.com/unpublishedpapers/searle.html

Jackson, Frank. 1982. Epiphenomenal qualia. Philosophical Quarterly 32: 127-36.

Jackson, Frank. 1986. What Mary didn't know? Journal of Philosophy 83: 291-5.

Kim, Jaegwon. 1978. Supervenience and nomological incommensurables. American Philosophical Quarterly 15: 149-56.

Kim, Jaegwon. 1984. Concepts of supervenience. Philosophy and Phenomenological Research 45(2): 153-76.

Kim, Jaegwon. 1990. Supervenience as a philosophical concept. Metaphilosophy 21(1-2): 1-27.

Kim, Jaegwon. 1993. Supervenience and Mind. New York: Cambridge University Press.

Levine, Joseph. 2001. Purple Haze: the Puzzle of Consciousness. Oxford, New York: Oxford University Press.

Lowe, Edward Jonathan. 2000. An Introduction to the Philosophy of Mind. Cambridge, New York: Cambridge University Press.

Moreland, James Porter. 1987. Scaling the Secular City. Baker Books.

Nagel, Thomas. 1995. Searle: why we are not computers. In Other Minds, ed. by T. Nagel. New York: Oxford UniversityPress.

Popper, Karl; Eccles, John. 1977. The Self and Its Brain. Springer International. Searle, John. 1992. The Rediscovery of the Mind. Cambridge, MA: The MIT Press. Searle, John. 2001. Rationality in Action. A Bradford book.

Searle, John. 2002. Why I am not a property dualist. Journal of Consciousness Studies 9(12): 57-64.

Searle, John. 2004. Mind: A Brief Introduction. New York, Oxford: Oxford University Press.

Searle, John. 2007. Dualism revisited. Journal of Physiology_Paris 101: 169-78.

Velmans, Max. 2000. Understanding Consciousness. London: Routledge. 